\title{
CASTEP Study on Electronic and Optical Properties of Zinc Oxide
}

\author{
Hassan Soleimani ${ }^{1 *}$, Baig $\mathbf{M}^{1}$, Yahya $\mathbf{N}^{1}$ and Sabet $\mathbf{M}^{2}$ \\ ${ }^{1}$ Fundamental and Applied Sciences Department, Universiti Teknologi Petronas, Malaysia \\ ${ }^{2}$ Department of Petroleum and Chemical Engineering, Institute Teknologi Brunei (ITB), Brunei \\ Submission: March 23, 2017 ; Published: May 30, 2017
}

*Corresponding author: Hassan Soleimani, Fundamental and Applied Sciences Department, UniversitiTeknologi PETRONAS, Bandar Seri Iskandar 32610 Tronoh, Perak, Malaysia, Email: hassan.soleimani@utp.edu.my

\begin{abstract}
We investigate the effect of size on the electronic and optical properties of zinc oxide(ZnO). CASTEP simulations based on density functional theory has been performed to find the band structure, density of states and optical properties of zinc oxide(ZnO) bulk and nanocluster. The results show quantum confinement effect as band structure show discrete lines. The change in band gap has been observed from $0.822 \mathrm{eV}$ to $0.013 \mathrm{eV}$. Band structure calculations show Fermi level shift towards conduction band. Optical properties display low value of absorption in nanocluster as compared to bulk. ZnO nanocluster show high value of dielectric function compared to bulk. The results demonstrate high response of $\mathrm{ZnO}$ cluster in electromagnetic waves.
\end{abstract}

Keywords: Castep; Electronic; Optical; Zinc Oxide

Abbreviations: ZnO: zinc oxide; 0D: zero-dimensional; DFT: density functional theory; GGA: generalized gradient approximation

\section{Introduction}

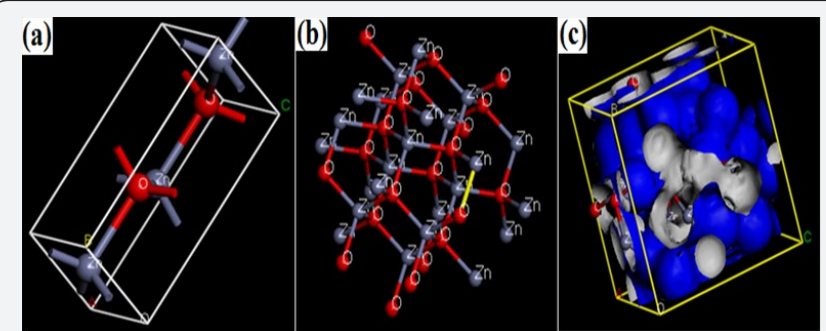

Figure 1: $\mathrm{ZnO}$ (a) unit cell (b) Nanocluster and (c) electron density around cluster.

Zinc oxide $(\mathrm{ZnO})$ is a promising direct wide band gap semiconductor, which has many advantages such as good optical, electronic properties and low cost [1,2]. ZnO has received considerable attention as a potential solar material due to its photostability and excellent charge transport [3]. Currently, a significant amount of theoretical research is being devoted to $\mathrm{ZnO}$ nanoparticles (Figure 1). In particular, zero-dimensional (OD) $\mathrm{ZnO}$ nanostructures such as nanoparticles have attracted considerable attention because they would have improved applications for their large surface-to-volume ratio, controllable shapes and quantum confinement effect [4]. The 0D $\mathrm{ZnO}$ nanostructures have been synthesized by various methods and characterized to have some unique properties. In contrast to the large amount of experimental investigations, only few theoretical studies on the nano structural $\mathrm{ZnO}$ have been done so far (Figure 2). In this regard, ab-initio calculations have contributed to explore the electronic structures of $\mathrm{ZnO}$ nanocluster and bulk for their promising application in building nano devices [5-9]. Theoretically, their structure, electronic, and optical properties have also been investigated.

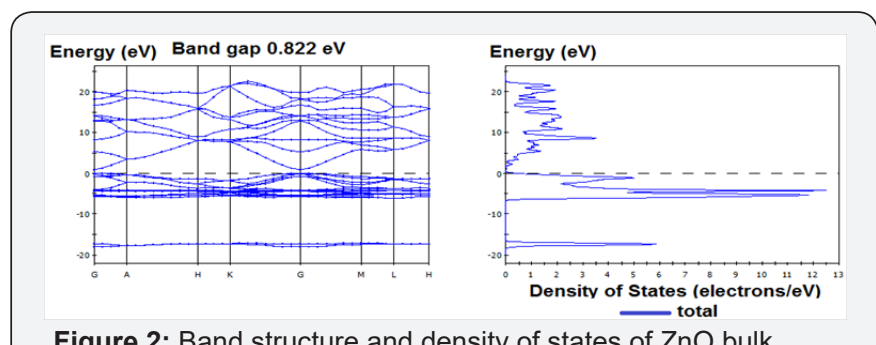

Figure 2: Band structure and density of states of $\mathrm{ZnO}$ bulk.

In this paper, we first calculated the band structure, density of states and optical properties of $\mathrm{ZnO}$ nanocluster and bulk by using CASTEP code based on density functional theory (DFT) (Figure 3). The electronic and optical properties were calculated with the optimized structures. The photo catalysts are often semiconductors that contain transitionmetal or post-transition-metal ions with $\mathrm{d} 0$ or d10 electronic 
configuration as cations and along with VA or VIA group ions as counter anions $[4,10,11]$. As a semiconductor of this type, $\mathrm{ZnO}$ is a low cost and environmentally friendly material with predominant chemical and physical properties, thus it has been widely used as photo catalyst (Figure 4). So, we also discussed the photo catalytic activity of $\mathrm{ZnO}$ nancluster following the part of optical properties.

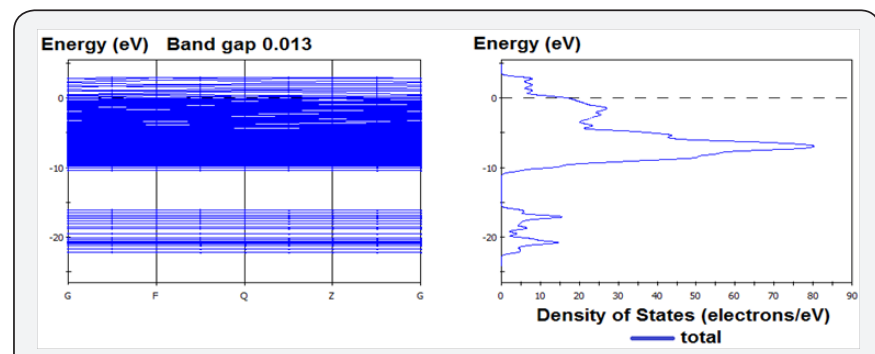

Figure 3: Band structure and density of States of $\mathrm{ZnO}$ nanocluster.

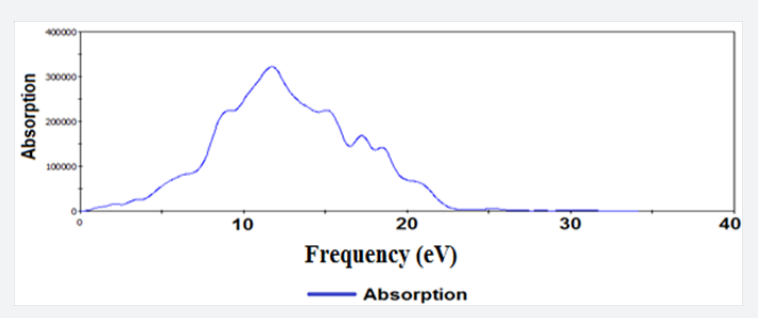

Figure 4: Absorption spectra of $\mathrm{ZnO}$ bulk.

\section{Computational Method}

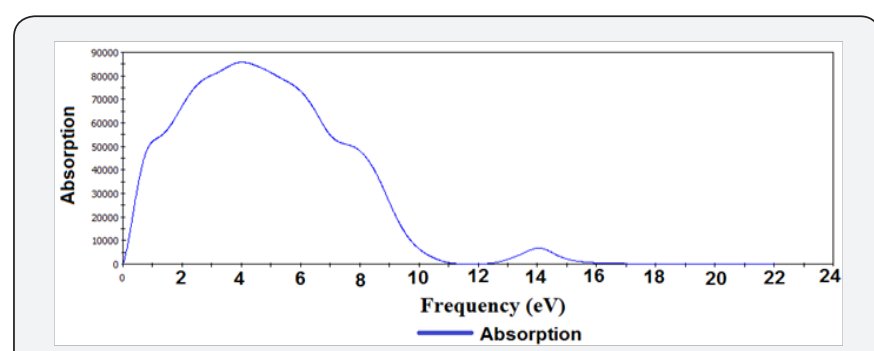

Figure 5: Absorption spectra of $\mathrm{ZnO}$ nanocluster.

In the present work, CASTEP module of Accelrys material studio based on density function theory and plane wave pseudopotential method was used to perform simulations [12]. Zinc oxide structure was imported and simulations were performed for band structure, density of states and optical properties. The (Figure 5) shows the imported structure of $\mathrm{ZnO}$, build nanocluster and electron density around nanocluster. The ground state geometries for $\mathrm{ZnO}$ were relaxed using CASTEP (Figure 6). With CASTEP, the wave functions of valence electrons were expanded in a plane wave basis set with $\mathrm{k}$ vectors within a specified energy cutoff [13]. The core region and valence electrons of the atoms in the super cell of intrinsic $\mathrm{ZnO}$ are described within the generalized gradient approximation (GGA), employing the Perdew-Burke-Ernzerhof (PBE) functional form [14] (Figure 7).

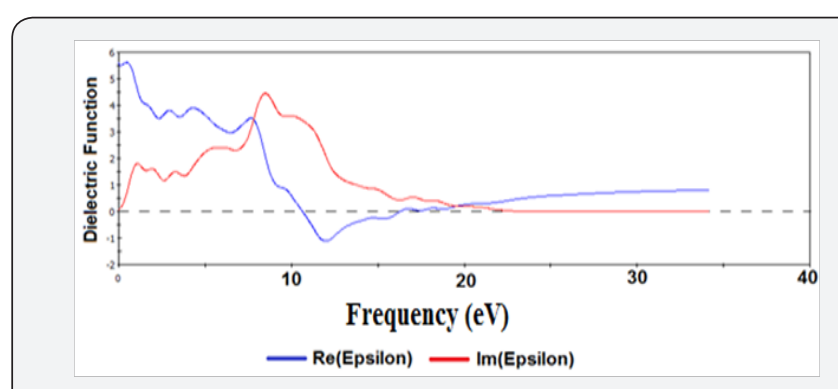

Figure 6: Real and imaginary dielectric Function of ZnO bulk.

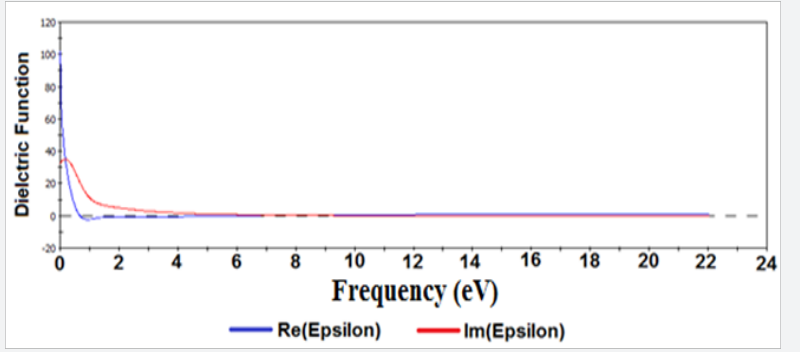

Figure 7: Dielectric Function of $\mathrm{ZnO}$ nanocluster.

\section{Results and Discussion}

Figure 2 and 3shows the band structure and density of states of $\mathrm{ZnO}$ bulk and nanocluster respectively. The results show reduction in band gap from $0.822 \mathrm{eV}$ to $0.013 \mathrm{eV}$. The band structure calculations of $\mathrm{ZnO}$ nanocluster show splitting of energy levels and shift in Fermi level as shown (Figure 8 \& 9).

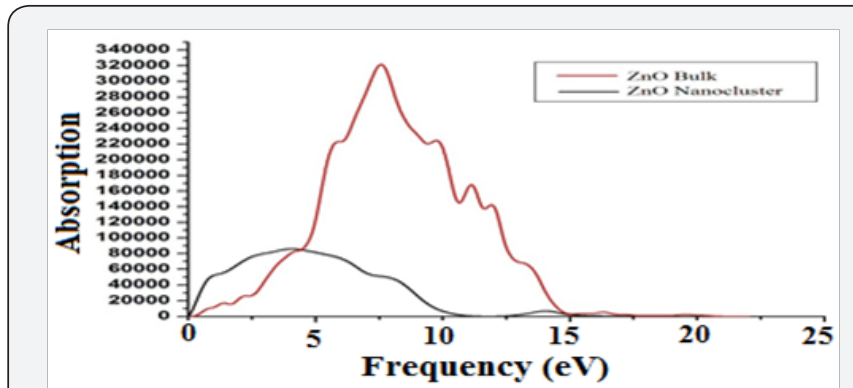

Figure 8: absorption spectra of $\mathrm{ZnO}$ bulk and nanocluster.

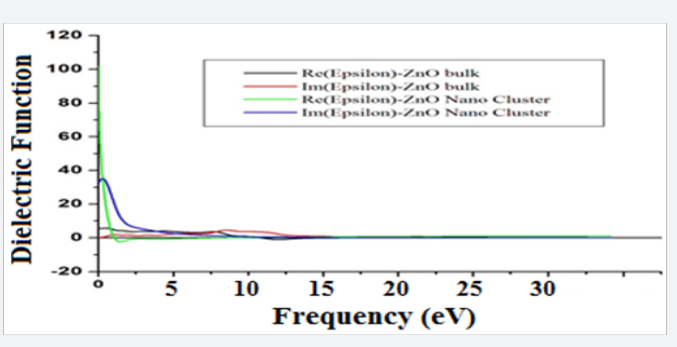

Figure 9: Comparison of dielectric Function of $\mathrm{ZnO}$ bulk and nanocluster. 


\section{Conclusion}

The CASTEP calculations based on the density function theory (DFT) have been carried out in studying the electronic and optical properties $\mathrm{ZnO}$ bulk and nanocluster. The results show reduction in band gap from $0.822 \mathrm{eV}$ to $0.013 \mathrm{eV}$ which means low energy required for transition between valence bands to conduction band. The $\mathrm{ZnO}$ nanocluster show low absorption as compared to bulk due to small band gap. The high dielectric function shows good response in electric field. The results show practical applications in nano fluids, photo voltaic sand solar cell.

\section{References}

1. Greene LE, Yuhas BD, Law M, Zitoun D, Yang P, et al. (2006) Solutiongrown zinc oxide nano wires. Inorg Chem 45(19): 7535-7543.

2. Soleimani H, Yahya N, Baig M, Khodapanah L, Sabet M, et al. (2016) Catalytic Effect Of Zinc Oxide Nanoparticles On Oil-Water Interfacial Tension Digest. Journal Of Nanomaterials And Bio structures 11(1): 263-269

3. Alias SS, Mohamad AA (2014) Synthesis of zinc oxide by sol-gel method for photo electro chemical cells.

4. Hassan Soleimani Za, Yahyaa N, Soleimani H, Sabet M, Oechsner A, et al (2015) An Optimisation Approch To Determine The Electromagnetic Properties Of Lanthanum Iron Garnet Filled Pdf-Polymer Composite At Microwave Frequencies. Digest Journal of Nanomaterials and Biostructures 10(3): 895-900.

5. Sakurai M, Wang Y, Uemura T, Aono M (2009) Electrical properties of individual ZnO nanowires. Nanotechnology 20(15): 155203.
6. She GW, Zhang XH, Shi WS, Fan X, Chang JC, et al. (2008) Controlled synthesis of oriented single-crystal ZnO nano tube arrays on transparent conductive substrates. Appl Phys Lett 92(5): 053111.

7. Liu P, She G, Liao Z, Wang Y, Wang Z, et al. (2009) Observation of persistent photo conductance in single $\mathrm{ZnO}$ nano tube. Appl Phys Lett 94(6): 063120.

8. Chai G, Lin C, Wang J, Zhang M, Wei J, et al. (2011) Density functional theory simulations of structures and properties for Ag-doped $\mathrm{ZnO}$ nano tubes. The Journal of Physical Chemistry C 115(7): 2907-2913.

9. Soleimani H, Yahya N, Latiff NRA, Zaid HM, Demiral B, et al. (2014) Novel enhanced oil recovery method using $\mathrm{Co}^{2+} \mathrm{xFe}^{2+}{ }_{1-x} \mathrm{Fe}^{3+}{ }_{2} \mathrm{O}_{4}$ as magnetic nanoparticles activated by electromagnetic waves. In Journal of Nano Research 26(2014): 111-116.

10. Tsuji I, Kato H, Kudo A (2006) Photo catalytic hydrogen evolution on $\mathrm{ZnS} \mathrm{CuInS}_{2}-\mathrm{AgInS}_{2}$ solid solution photo catalysts with wide visible light absorption bands. Chemistry of Materials 18(7): 1969-1975.

11. Maeda K, Teramura K, Lu D, Takata T, Saito N, et al. (2006) Photo catalyst releasing hydrogen from water. Nature 440(7082): 295.

12. Payne MC, Teter MP, Allan DC, Arias T, Joannopoulos J, et al. (1992) Iterative minimization techniques for ab initio total-energy calculations: molecular dynamics and conjugate gradients. Reviews of Modern Physics 64(4): 1992.

13.Zhu Z, Chutia A, Sahnoun R, Koyama M, Tsuboi H, et al. (2008) Theoretical study on electronic and electrical properties of nano structural ZnO. Japanese Journal of Applied Physics 47(4S): 2999.

14. Jaffe JE, Snyder JA, Lin Z, Hess AC (2000) LDA and GGA calculations for high-pressure phase transitions in $\mathrm{ZnO}$ and $\mathrm{MgO}$. Physical Review B 62: 1660 .

\section{Your next submission with Juniper Publishers will reach you the below assets}

- Quality Editorial service

- Swift Peer Review

- Reprints availability

- E-prints Service

- Manuscript Podcast for convenient understanding

- Global attainment for your research

- Manuscript accessibility in different formats

( Pdf, E-pub, Full Text, Audio)

- Unceasing customer service

Track the below URL for one-step submission https://juniperpublishers.com/online-submission.php 